\title{
The Combination of Icotinib Hydrochloride and Fluzoparib Enhances the Radiosensitivity of Biliary Tract Cancer Cells
}

This article was published in the following Dove Press journal: Cancer Management and Research

\author{
Linggang Zhu',2 \\ Chu Zhu' \\ Xuanxuan Wang' \\ Hai Liu' \\ Yanhong Zhu' \\ Xiaonan Sun (iD) \\ 'Department of Radiation Oncology, Sir \\ Run Run Shaw Hospital, School of \\ Medicine, Zhejiang University, Hangzhou, \\ People's Republic of China; ${ }^{2}$ Department \\ of Radiation Oncology, Taizhou Cancer \\ Hospital, Taizhou, Zhejiang Province, \\ People's Republic of China
}

Correspondence: Xiaonan Sun Department of Radiation Oncology, Sir Run Run Shaw Hospital, School of Medicine, Zhejiang University, 3 Qingchun East Road, Hangzhou Zhejiang Province 310000 , People's Republic of China

Tel +8657186096916

Fax +865718604 4817

Email sunxiaonan@zju.edu.cn
Background: Radiotherapy and chemotherapy are the main clinical treatments for biliary tract cancers (BTCs). Patients with advanced disease have a very poor prognosis, yet no molecular targets have been proven effective for the adjuvant therapy of BTCs. In this study, we aimed to explore the effect of combination treatment with icotinib hydrochloride (IH) and fluzoparib (FZ) on radiosensitivity and clarify its underlying mechanism in the HCCC-9810 and GBC-SD human BTC cell lines.

Methods: Cell proliferation was measured by Cell Counting Kit-8 (CCK-8) assay. The cell cycle distribution and apoptosis were analyzed by flow cytometry. The phosphorylation of EGFR and its downstream signaling molecules and the expression of RAD51 were measured by Western blot analysis. $\gamma$-H2AX foci in the cellular nuclei were visualized using immunofluorescence staining. A colony formation assay was performed to demonstrate cell radiosensitivity with $\mathrm{IH}$ and $\mathrm{FZ}$ combination treatment.

Results: In the HCCC-9810 and GBC-SD human BTC cell lines, combined treatment with $\mathrm{IH}$ and $\mathrm{FZ}$ with synergetic radiation significantly inhibited cell proliferation, redistributed the cell cycle, enhanced apoptosis and delayed DNA damage repair by suppressing activation of the EGFR signaling pathway and attenuating expression of the homologous recombination (HR) protein RAD51.

Conclusion: This study demonstrates that combined treatment with IH and FZ may be an applicable therapy to enhance the radiosensitivity of BTCs and that RAD51 may serve as a biomarker for this combination treatment.

Keywords: icotinib hydrochloride, fluzoparib, biliary tract cancer, EGFR, PARP, radiotherapy

\section{Introduction}

Biliary tract cancers (BTCs) include gallbladder cancer and intrahepatic and extrahepatic cholangiocarcinoma. Complete resection with negative margins is the only potential curative therapy for patients with resectable disease, but most cases are inoperable. Patients with BTC commonly present with advanced disease and a very poor prognosis. Chemotherapy can improve the quality of life of patients with unresectable, recurrent or metastatic BTCs. Radiation therapy and fluoropyrimidine chemoradiation are options for patients with unresectable disease. Radiotherapy plays an important role in the treatment of BTCs and improves the local control rate. Ionizing radiation (IR) induces DNA damage mainly caused by double-stranded DNA breaks (DSBs), which can then be repaired by non-homologous end joining 
(NHEJ) and homologous recombination (HR), the most important DSB repair pathway. ${ }^{1}$ RAD51 is an effective protein that plays a central role in catalyzing the homologous recombination process. ${ }^{2}$ The elevated expression of RAD51 is associated with an increase in cell proliferation, radiotherapy resistance and poor prognosis in multiple cancer types, including BTC., ${ }^{3,4}$ Inhibition of RAD51 expression was shown to correlate with increased radiosensitivity. In contrast to other solid tumors, no molecular target has been approved as effective for the chemotherapy of BTCs, but some, such as EGFR tyrosine kinase inhibitors (EGFRTKIs) ${ }^{5}$ and PARP inhibitors (PARPis), ${ }^{6}$ have been demonstrated to improve radiosensitivity. EGFR is a cell-surface tyrosine kinase receptor belonging to the ErbB family, and the activation of downstream EGFR signaling pathways enhances cellular survival, proliferation, angiogenesis and metastasis. ${ }^{7}$ PARP1 accounts for at least $85 \%$ activity of cellular PARP (Poly-ADP ribose polymerase), which is involved in double-strand DNA repair, transcriptional regulation, and also involved in single-stranded DNA break (SSB) repair. ${ }^{8}$ Inhibition of PARP activity prevents the repair of SSBs, which could then be converted to DSBs during subsequent DNA replication. Then, these breaks are normally repaired by RAD51-related HR using the sister chromatids as templates. ${ }^{9}$

Icotinib hydrochloride (IH) is a first-generation oral EGFR-TKI that was developed by Zhejiang Beta Pharma Co., Ltd. (Hangzhou, China) and approved as effective for advanced non-small cell lung cancer (NSCLC) patients in 2011 by the State Food and Drug Administration (SFDA) of China. Fluzoparib (FZ) is an oral PARPi that was developed by Jiangsu Hengrui Medicine Co., Ltd. (Shanghai, China), and a new drug application for FZ was accepted by the National Medical Products Administration (NMPA) of China in 2019. Fluzoparib was studied in a Phase III clinical trial for the treatment of recurrent ovarian cancer (CTR20190294). In this study, we not only investigated the radiosensitization of BTC to icotinib hydrochloride (IH) combined with fluzoparib (FZ) in vitro but also clarified the potential mechanism by which EGFR signaling pathway is inhibited and RAD51 expression is changed with this combination therapy.

\section{Materials and Methods}

\section{Reagents}

The EGFR-TKI icotinib hydrochloride (IH) was kindly provided by Zhejiang Beta Pharma Co., Ltd. The PARPi fluzoparib (FZ) was kindly provided by Jiangsu Hengrui Medicine Co., Ltd. The two inhibitors were dissolved in $100 \%$ dimethyl sulfoxide (DMSO) (Solarbio) to $50 \mathrm{mM}$ and stored at $-20^{\circ} \mathrm{C}$. Cell Counting Kit-8 (CCK-8) reagent was obtained from Dojindo Laboratories (Kumamoto, Japan). An Annexin V-APC/7-AAD apoptosis kit was obtained from Multi Sciences (Shanghai, China). A BCA protein assay kit was obtained from Beyotime. RNAiso Plus Reagent was obtained from Takara (Dalian, China). SYBR $^{\circledR}$ qPCR Master Mix was obtained from Vazyme. Antiphospho-EGFR (Y1068), anti-EGFR, anti-phospho-AKT (S473), anti-AKT, anti-phospho-MAPK (Y204), antiMAPK, and anti-PARP1 antibodies were purchased from Cell Signaling Technology (Danvers, MA, USA). AntiRAD51, anti- $\gamma$-H2AX, anti- $\beta$-tubulin, and anti- $\beta$-actin antibodies were purchased from Abcam (Cambridge, MA, USA).

\section{Cell Lines and Cell Culture}

The human BTC cell lines HCCC-9810 and GBC-SD were purchased from the Shanghai Institute of Biochemistry and Cell Biology, Chinese Academy of Sciences (Shanghai, China). All cells were cultured in RPMI 1640 medium (Thermo Fisher Scientific, Waltham, MA, USA) supplemented with $10 \%$ fetal bovine serum (Thermo Fisher Scientific) and $100 \mathrm{mg} / \mathrm{mL}$ penicillin/streptomycin (Solarbio, Beijing, China) at $37^{\circ} \mathrm{C}$ in a humidified atmosphere with $5 \% \mathrm{CO}_{2}$.

\section{Cell Counting Kit-8 (CCK-8) Assay}

Cells were seeded at a density of $5 \times 10^{3}$ cells/well in 96well cell culture plates and incubated overnight in $100 \mu \mathrm{L}$ of RPMI 1640 medium. In the following days, DMSO, IH, FZ or $\mathrm{IH}+\mathrm{FZ}$ at different concentrations were added 4 hours before irradiation (0 Gy, 2 Gy, 4 Gy and 6 Gy) with $6 \mathrm{MV}$ X-rays at a dose rate of $2 \mathrm{~Gy} / \mathrm{min}$ generated by a linear accelerator (Siemens, Erlangen, Germany). To measure the cell viability at the indicated time point, $10 \mu \mathrm{L}$ of CCK-8 reagent (Dojindo Laboratories, Kumamoto, Japan) was added to each well, and the cells were incubated at $37^{\circ} \mathrm{C}$ for 2.5 hours. Optical density (OD) values at a wavelength of $450 \mathrm{~nm}$ were measured by a microplate reader (Thermo Fisher Scientific).

\section{Flow Cytometry Analysis}

For cell cycle analysis, DMSO, IH, FZ or IH+FZ at different concentrations were added to cells 4 hours before irradiation (6 Gy), and the cells were cultured for 24 hours, 
harvested and washed twice with ice-cold PBS. After being fixed in $70 \%$ cold ethanol at $4{ }^{\circ} \mathrm{C}$ overnight, the cells were stained with propidium iodide in the presence of RNase A at $37^{\circ} \mathrm{C}$ for 30 minutes. The stained cells were analyzed with a flow cytometer (BD Biosciences, San Jose, CA, USA), and the results of cell cycle distribution analysis were analyzed by ModFit LT software.

For apoptosis analysis, cells were treated with drugs at different concentrations 4 hours before IR, cultured for 72 hours, and then analyzed using the Annexin V-APC/ 7-AAD apoptosis kit (Multi Sciences, Shanghai, China) according to the manufacturer's protocol. The stained cells were detected with a flow cytometer (BD Biosciences, San Jose, CA, USA), and the results were analyzed with FlowJo vX 0.7 software.

\section{Colony Formation Assay}

A colony formation assay was performed to determine radiosensitivity. Cells were seeded in 6-well cell culture plates, allowed to adhere overnight, and then treated with agents for 4 hours, followed by exposure to irradiation ( 0 Gy, 1 Gy, 2 Gy, 4 Gy, 6 Gy). The cells were further incubated for 10-14 days, fixed in $75 \%$ ethanol for 15 minutes, and then stained with $0.5 \%$ crystal violet. Colonies (a population of $>50$ cells) were counted using microscopy. The survival curves were plotted by linear regression analysis, and the radiosensitivity parameter was calculated using GraphPad Prism v6 software. The D0 and sensitizing enhancement ratio (SER) were calculated as previously described. ${ }^{10}$

\section{Western Blotting}

Cells were treated with agents at different concentrations for 4 hours, followed by exposure to IR (6 Gy) and further culture for 24 hours. The cells were then harvested and lysed in RIPA buffer (Beyotime) containing 1\% phosphatase inhibitor for total protein extraction. After quantification using the Pierce BCA protein assay kit (Thermo Fisher Scientific) and boiling for 10 minutes at $95^{\circ} \mathrm{C}$ in loading buffer containing SDS, samples containing equal amounts of protein were separated via SDS-PAGE and transferred to polyvinylidene difluoride membranes. The membranes were incubated with the respective primary antibodies at $4^{\circ} \mathrm{C}$ overnight and then exposed to HRPconjugated secondary antibodies for 1 hour at room temperature. Primary antibodies against the following were used: EGFR/p-EGFR, AKT/p-AKT, MAPK/p-MAPK, PARP1, RAD51, $\gamma$-H2AX, $\beta$-tubulin, $\beta$-actin.

\section{Immunofluorescence Staining}

Cells were seeded on coverslips and treated with agents at different concentrations for 4 hours, followed by exposure to IR (6 Gy). At the indicated time points $(0,0.5,1,2,4,8,12$, 24,48 hours), the cells were fixed with $4 \%$ paraformaldehyde for 20 minutes and then permeabilized with a $0.3 \%$ Triton solution for 20 minutes on ice. After blocking with 5\% BSA, the coverslips were stained with anti- $\gamma-\mathrm{H} 2 \mathrm{AX}$ (Ser139) overnight at $4{ }^{\circ} \mathrm{C}$ and then incubated with Alexa Fluor ${ }^{\circledR}$ dyeconjugated secondary antibody (Abcam) for 2 hours at room temperature. Cell nuclei were counterstained with DAPI for 1 minute and visualized using an Axiovert 200M inverted microscope (Zeiss, Oberkochen, Germany).

\section{RNA Isolation and Quantitative Reverse Transcription Polymerase Chain Reaction (qRT-PCR)}

Total RNA was extracted from the cell lines using RNAiso Plus reagent (Takara, Dalian, China) and reverse transcribed using the HiScript ${ }^{\circledR}$ QRT SuperMix for qPCR kit (Vazyme). Then, qRT-PCR was performed using the $\mathrm{SYBR}^{\circledR}$ qPCR Master Mix kit (Vazyme). The primer sequences used for specific gene amplification were as follows:

EGFR primer:

Forward - CGGGCTCTGGAGGAAAAGAA

Reverse - TGCGTGAGCTTGTTACTCGT

PARP primer:

Forward - CCCCACGACTTTGGGATGAA

Reverse - AGACTGTAGGCCACCTCGAT.

\section{Statistical Analysis}

Statistical analysis was performed with SPSS software. All results are expressed as the mean $\pm \mathrm{SD}$, and $\mathrm{P}<0.05$ indicates significance.

\section{Results}

Icotinib Hydrochloride $(\mathrm{IH})$ and Fluzoparib (FZ) Enhanced Radiation-Induced Proliferation Inhibition in BTC Cells

To detect the inhibitory effect of icotinib hydrochloride (IH) and fluzoparib (FZ) on the proliferation of BTC cells, the HCCC-9810 and GBC-SD cell lines were applied, and the $20 \%$ inhibitory concentrations (IC20 values) of IH and FZ used for the study were selected by CCK-8 assay (Figure S1A and B), and the applied concentration was further adjusted for appropriate applications in combination with radiotherapy and 
also the culturing time was considered. Both cell lines were divided into the following eight groups: $\mathrm{Ctrl}$ (DMSO), IH, FZ, IH+FZ, IR, IH+IR, FZ+IR and IH+FZ+IR. HCCC-9810 cells were incubated with $1 \mu \mathrm{M} \mathrm{IH}, 10 \mu \mathrm{M} \mathrm{FZ}$, and $1 \mu \mathrm{M} \mathrm{IH}+10$ $\mu \mathrm{M}$ FZ. GBC-SD cells were incubated with $3 \mu \mathrm{M}$ IH, $30 \mu \mathrm{M}$ $\mathrm{FZ}$, and $3 \mu \mathrm{M} \mathrm{IH}+30 \mu \mathrm{M}$ FZ. Four hours later, the groups subjected to IR treatment received 6 Gy radiotherapy. Cell viability at $0,24,48$ and 72 hours after irradiation was evaluated by CCK-8 assay for cell proliferation analysis. First, combination treatment with $\mathrm{IH}$ and $\mathrm{FZ}$ significantly suppressed cell proliferation in both the HCCC-9810 and GBCSD cells compared to proliferation upon treatment with either $\mathrm{IH}$ or FZ (Figure 1A and B). Second, the cell proliferation rate of the IR-treated HCCC-9810 and GBC-SD cells was decreased by combination treatment compared to that with treatment with IH or FZ. Furthermore, under irradiation, compared to IR monotherapy, the dual combination of the drugs IH and FZ significantly suppressed cell proliferation in both HCCC-9810 and GBC-SD cells ( $<<0.001)$. These results suggest that both $\mathrm{IH}$ and $\mathrm{FZ}$ inhibited cell proliferation in either IR-treated or untreated cells and that the dual combination drug treatment had a significant antiproliferative effect.

\section{Effects of $\mathrm{IH}$ and $\mathrm{FZ}$ on \\ Irradiation-Induced Cell Cycle Arrest}

The effects of $\mathrm{IH}$ and $\mathrm{FZ}$ on the cell cycle distribution in vitro were detected by flow cytometry, and HCCC-9810/GBC-SD cells were again divided into the following eight groups for treatment: Ctrl, IH, FZ, IH+FZ, IR, IH+IR, FZ+IR and IH+FZ
+IR. All groups were starved in serum-free medium for 24 hours before the treatments. HCCC-9810 cells were incubated with $10 \mu \mathrm{M} \mathrm{IH}, 20 \mu \mathrm{M} \mathrm{FZ}$, and $10 \mu \mathrm{M} \mathrm{IH}+20 \mu \mathrm{M}$ FZ before 6 Gy irradiation. GBC-SD cells were incubated with $15 \mu \mathrm{M}$ $\mathrm{IH}, 5 \mu \mathrm{M} \mathrm{FZ}$, and $15 \mu \mathrm{M} \mathrm{IH}+5 \mu \mathrm{M}$ FZ before 4 Gy irradiation. Among HCCC-9810 cells, the population of cells at G1 phase was increased by $\mathrm{IH}$ treatment compared with that among the control cells $(\mathrm{p}<0.01)$, while FZ treatment had the opposite effect and induced $\mathrm{G} 2$ and $\mathrm{S}$ phase blockade (Figure 2A and C). In GBC-SD cells, the changes in the cell cycle with $\mathrm{IH}$ were not significant, while treatment with FZ alone increased the population of cells at $\mathrm{G} 2$ phase (Figure 2B and D). Blockade of G2 phase induced by IR treatment was detected in both HCCC-9810 and GBC-SD cells. In irradiated HCCC-9810 cells, under IH, FZ or IH+FZ combined pretreatment, $\mathrm{S}$ phase arrest was prolonged compared to that under treatment with IR alone $(2.02 \% \pm 0.5 \%$ vs $4.07 \% \pm 0.58 \%$, $10.17 \% \pm 8.12 \%, 15.06 \% \pm 13.08 \%$, respectively). In irradiated GBC-SD cells, the S phase was also prolonged by IH, FZ and $\mathrm{IH}+\mathrm{FZ}$ combined treatment compared to that with IR alone $(13.03 \%$ vs $15.14 \%, 16.42 \%, 21.97 \%$, respectively). Collectively, these results indicate that combined IH and FZ treatment with radiotherapy could induce cell cycle redistribution, especially $\mathrm{S}$ phase arrest, and inhibit cell proliferation.

\section{Effects of IH and FZ on Cell Apoptosis Following Irradiation Treatment}

Flow cytometry was further applied to evaluate whether IH and FZ could increase radiotherapy-induced apoptosis.
A

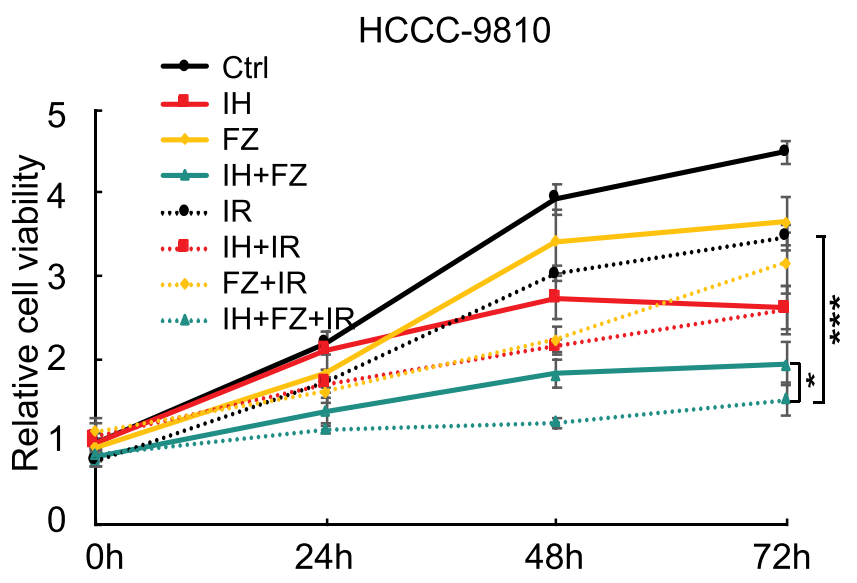

B

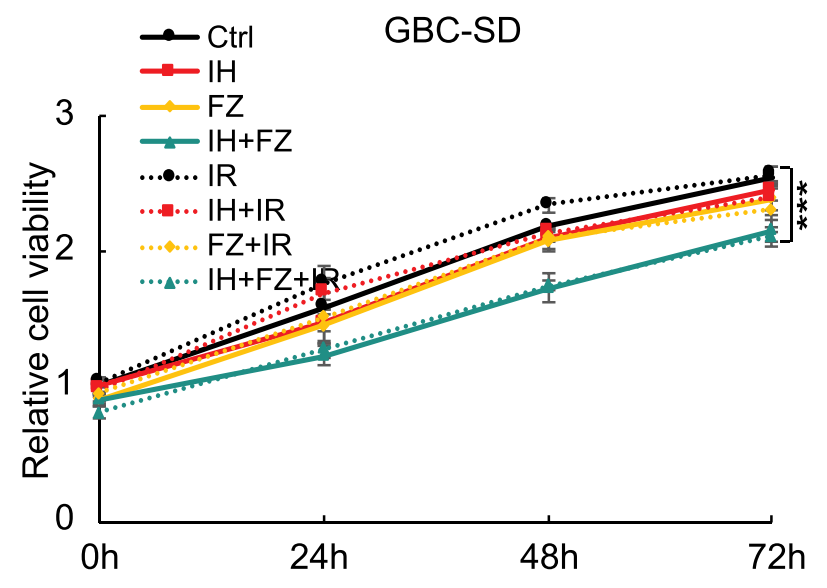

Figure I Icotinib hydrochloride (IH) and fluzoparib (FZ) enhanced the radiation-induced inhibition of BTC cell proliferation. (A) Cell proliferation of HCCC-98I0 cells in the 72 hours after treatment with I $\mu \mathrm{MIH}, 10 \mu \mathrm{M} \mathrm{FZ}$, and I $\mu \mathrm{MIH}+10 \mu \mathrm{M}$ FZ at 4 hours before 6 Gy irradiation. (B) Cell proliferation of GBC-SD cells in the 72 hours

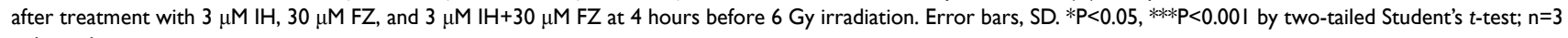
independent experiments.

Abbreviations: Ctrl, control; IH, icotinib hydrochloride; FZ, fluzoparib; IR, ionizing radiation; CCK-8, Cell Counting Kit-8; h, hour; BTC, biliary tract cancer. 


\section{A HCCC-9810 Ctrl}

$\mathrm{IH}$

FZ

$\mathrm{IH}+\mathrm{FZ}$

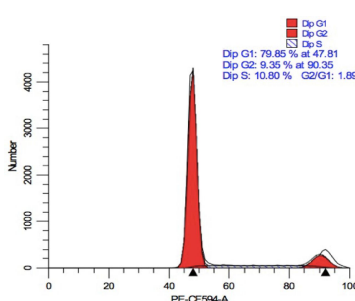

IR

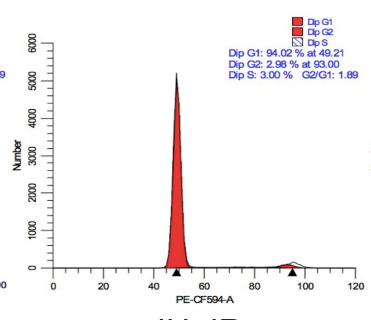

$\mathrm{IH}+\mathrm{IR}$

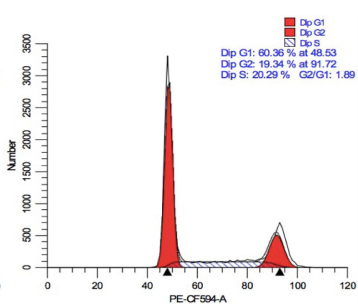

$F Z+I R$

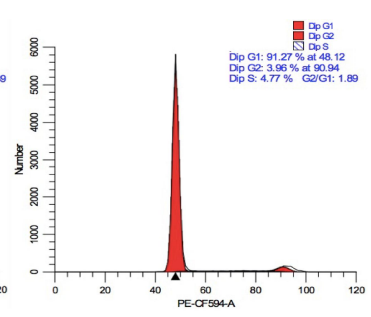

$\mathrm{IH}+\mathrm{FZ}+\mathrm{IR}$
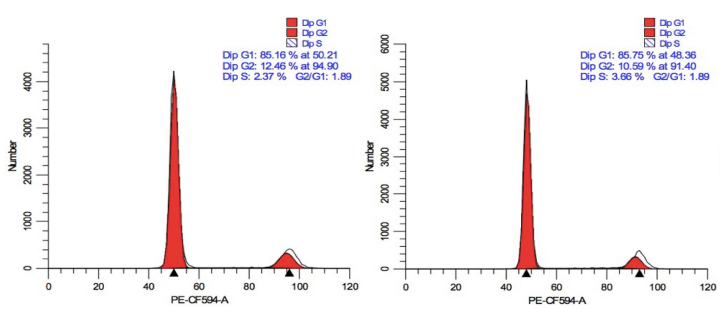

$\mathrm{IH}$

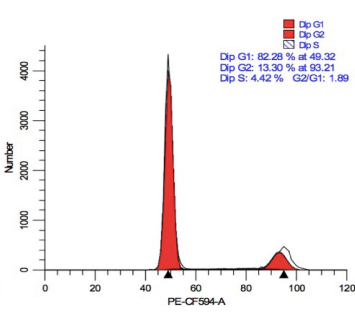

$F Z$

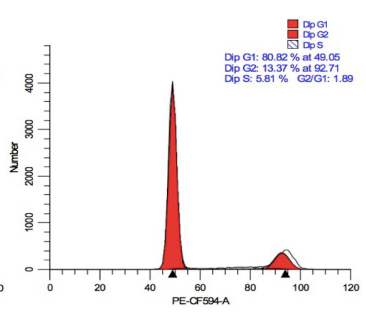

B GBC-SD Ctrl

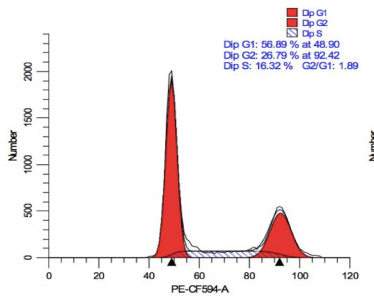

IR

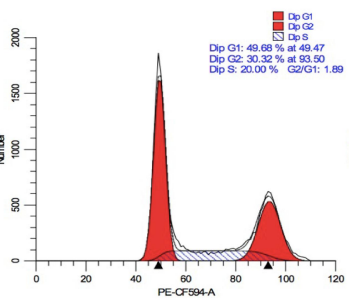

$\mathrm{IH}+\mathrm{IR}$

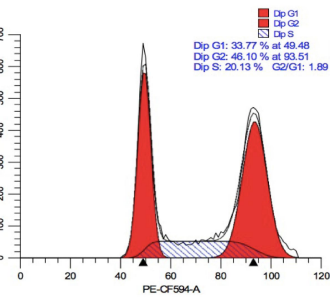

$F Z+I R$

$\mathrm{IH}+\mathrm{FZ}$

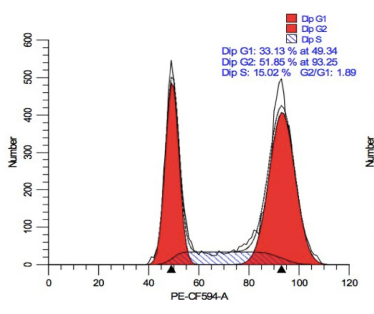

C

HCCC-9810

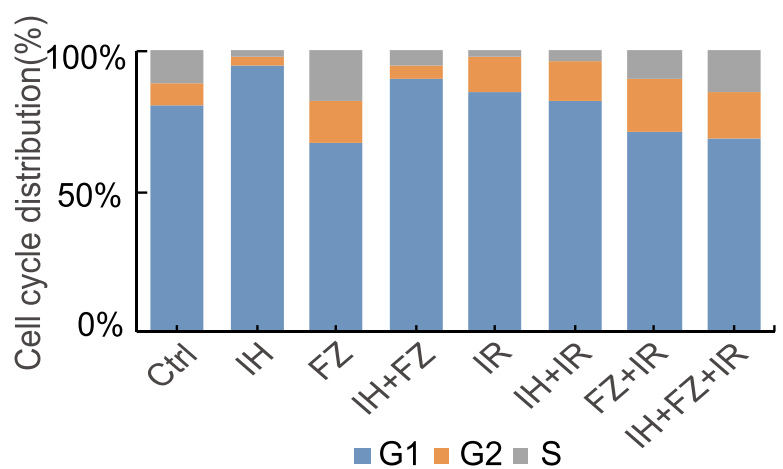

GBC-SD

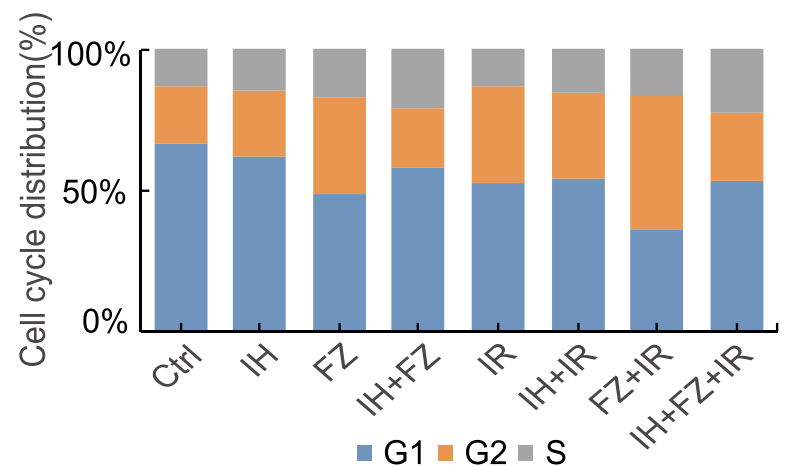

Figure 2 Effects of icotinib hydrochloride $(\mathrm{IH})$ and fluzoparib $(\mathrm{FZ})$ on irradiation-induced cell cycle arrest. (A and $\mathbf{B})$ The cell cycle distribution in the following groups was detected by flow cytometry: HCCC-98I0 cells pretreated with $10 \mu \mathrm{MIH}, 20 \mu \mathrm{M}$ FZ, or $10 \mu \mathrm{MIH}+20 \mu \mathrm{M}$ FZ at 4 hours before $6 \mathrm{~Gy}$ irradiation; GBC-SD cells pretreated with $15 \mu \mathrm{M} \mathrm{IH}, 5 \mu \mathrm{M} \mathrm{FZ}$, or $15 \mu \mathrm{MIH}+5 \mu \mathrm{M}$ FZ at 4 hours before $4 \mathrm{~Gy}$ irradiation. (C and D) The proportion of HCCC-98I0 and GBC-SD cells at the GI, S and G2 phases of the cell cycle. Data are representative of at least duplicate experiments. 
HCCC-9810 cells were incubated with $10 \mu \mathrm{M}$ IH, $20 \mu \mathrm{M}$ $\mathrm{FZ}$, and $10 \mu \mathrm{M} \mathrm{IH}+20 \mu \mathrm{M}$ FZ before 6 Gy irradiation.

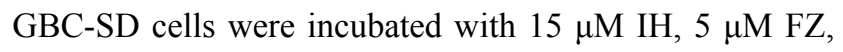
and $15 \mu \mathrm{M} \mathrm{IH}+5 \mu \mathrm{M}$ FZ before 6 Gy irradiation and harvested 72 hours later. Among HCCC-9810 cells, the proportion of apoptotic cells in the Ctrl group $3.43 \%$ $\pm 1.44 \%)$ was lower than that in the IR group $(6.93 \%$ $\pm 2.03 \%$ ), and the proportion of apoptotic cells was significantly increased in the IH+FZ+IR group $(37.8 \% \pm 3.07 \%$, $\mathrm{p}<0.01$ ) (Figure $3 \mathrm{~A}$ and $\mathrm{C}$ ). In GBC-SD cells, IH+FZ+IR combination treatment $(11.5 \% \pm 2.45 \%)$ augmented the proportion of apoptotic cells compared to that in the IR group $(9.2 \% \pm 2.17 \%)$ and control group $(6.57 \% \pm 1.22 \%)$ (Figure $3 \mathrm{~B}$ and $\mathrm{D})$. To further explore the effect on apoptosis, PARP1 and its cleavage were evaluated via WB. In HCCC-9810 cells, the relative protein expression of cleaved PARP1 was significantly increased in the $\mathrm{IH}+\mathrm{FZ}$ + IR group compared to the IR group (Figure 6E), but this difference was not significant in GBC-SD cells. Therefore, pretreatment with IH plus FZ significantly increased cell apoptosis induced by radiotherapy, which contributed to the enhanced radiotherapy efficacy.

\section{Dual IH and FZ Combination Drug Treatment Increases Radiosensitivity by Delaying DNA Damage Repair}

To further explore the influence of $\mathrm{IH}$ and $\mathrm{FZ}$ combination treatment on the radiosensitivity of BTC cell lines, colony formation assays were performed. The results confirmed the sensitizing effect of $\mathrm{IH}+\mathrm{FZ}$ combined with radiation in HCCC-9810 and GBC-SD cells, which grew fewer and smaller clones than those grown in the radiation monotherapy group (Figure 4A). We clearly concluded from the survival curves that combination $\mathrm{IH}$ and $\mathrm{FZ}$ treatment significantly increased the radiosensitivity of HCCC-9810 and GBC-SD cells (Figure 4B). The SER (sensitivity enhancement ratio) was calculated to be 1.27 for HCCC9810 cells and 1.50 for GBC-SD cells (Table 1).

The DNA damage repair efficiency after irradiation exposure was measured by $\gamma-\mathrm{H} 2 \mathrm{AX}$ focus formation assays. The $\gamma-\mathrm{H} 2 \mathrm{AX}$ focus number reflected DNA damage initiation and resolution in radiation-treated cells. We found that the $\gamma$ $\mathrm{H} 2 \mathrm{AX}$ focus number was significantly increased in the $\mathrm{IH}$ plus FZ combined radiotherapy group and that the disappearance of foci was retarded compared with that in the radiation group (Figure 5A and B). We further tested the $\gamma-\mathrm{H} 2 \mathrm{AX}$ protein level by Western blot assays, and the level of $\gamma$ -
$\mathrm{H} 2 \mathrm{AX}$ at 2 hours after irradiation was significantly increased in the $\mathrm{IH}+\mathrm{FZ}$ pretreatment group compared with the radiation group for both the HCCC-9810 and GBC-SD cell lines (Figure 6C). In summary, these results show that $\mathrm{IH}$ and $\mathrm{FZ}$ pretreatment following radiotherapy could significantly increase DNA damage and delay the repair of DNA damage, suggesting that combination therapy could improve radiosensitivity by retarding DNA damage repair.

\section{IH and FZ Inhibit Radiation-Induced Activation of the EGFR Signaling Pathway and Attenuate RAD5I Upregulation}

To investigate the mechanism of enhanced radiosensitivity by $\mathrm{IH}$ and FZ treatment in BTC cells, we evaluated the expression levels of EGFR and PARP1 in HCCC9810 and GBC-SD cells. The expression of EGFR and PARP1 was higher in GBC-SD cells than in HCCC-9810 cells at both the protein and mRNA levels (Figure $6 \mathrm{~A}$ and $\mathrm{B})$. Then, we examined the phosphorylation level of EGFR and its downstream signaling molecules AKT and MAPK after pretreatment with $\mathrm{IH}$ and $\mathrm{FZ}$ followed by irradiation (Figure 6C and D). Total-cell lysates were harvested at 2 hours and 24 hours after exposure to radiation (6 Gy). The data showed that radiotherapy significantly induced the strong phosphorylation of EGFR at 2 hours and phosphorylation of the downstream molecules AKT and MAPK at 24 hours after radiotherapy, while IH pretreatment not only inhibited the radiotherapy-enhanced phosphorylation of EGFR at 2 hours but also strongly diminished the phosphorylation of AKT and MAPK at 24 hours after radiotherapy. Under IH plus FZ pretreatment, the levels of AKT and MAPK phosphorylation due to radiotherapy were significantly diminished and further decreased compared to those in the IH+FZ group. These results indicated that IH plus FZ could inhibit the EGFR signaling pathway, which was induced by radiotherapy.

RAD51 is a key protein involved in DSB repair through the HR pathway, a DNA damage repair pathway that results in more stable genomic DNA than that repaired by the NHEJ pathway. Therefore, we analyzed the effects of IH and FZ on RAD51 protein expression. The results showed that radiation increased the expression of RAD51, and IH and FZ pretreatment followed by radiation significantly diminished the upregulation of RAD51 expression (Figure 6D). These results demonstrate that $\mathrm{IH}$ combined with FZ could suppress RAD51 expression, which may 
A

HCCC-9810 Ctrl

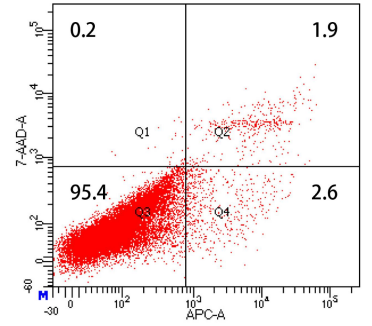

IR

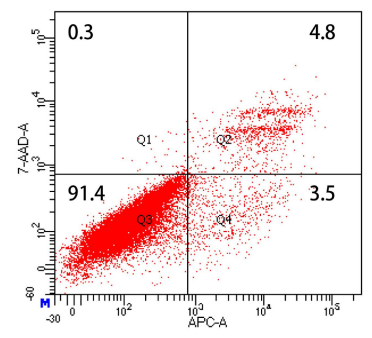

B

GBC-SD Ctrl

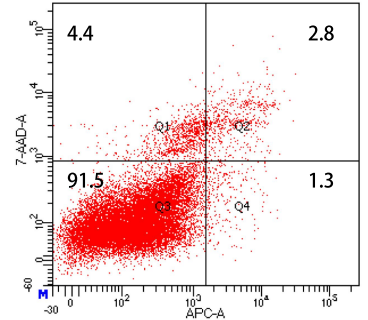

IR

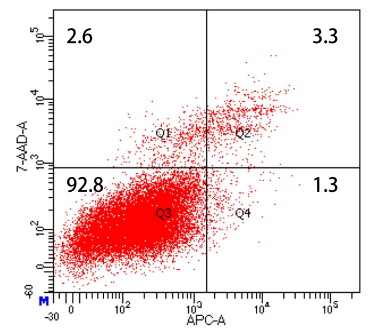

C

HCCC-9810

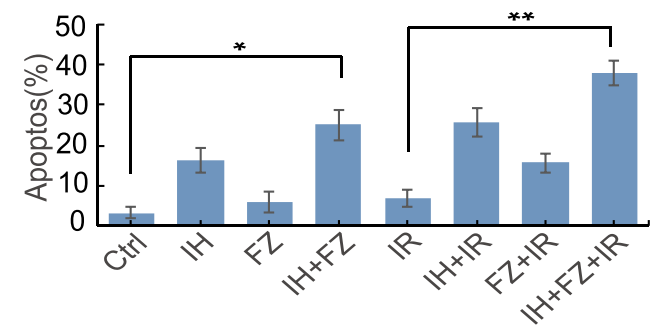

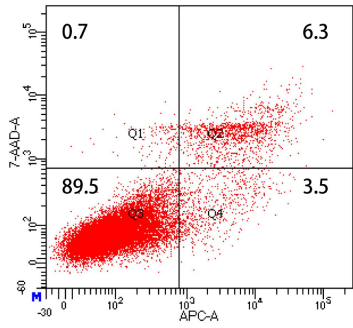

$\mathrm{IH}+\mathrm{IR}$

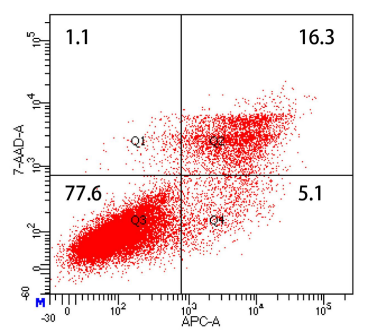

$\mathrm{IH}$

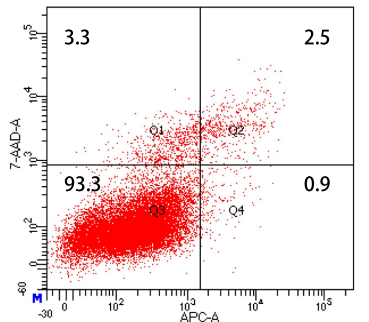

IH+IR
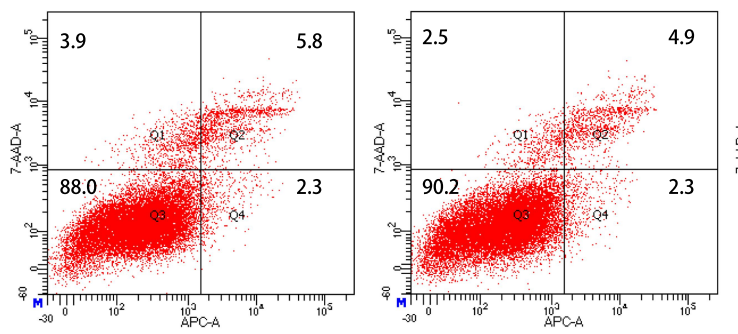

FZ

$\mathrm{IH}+\mathrm{FZ}$
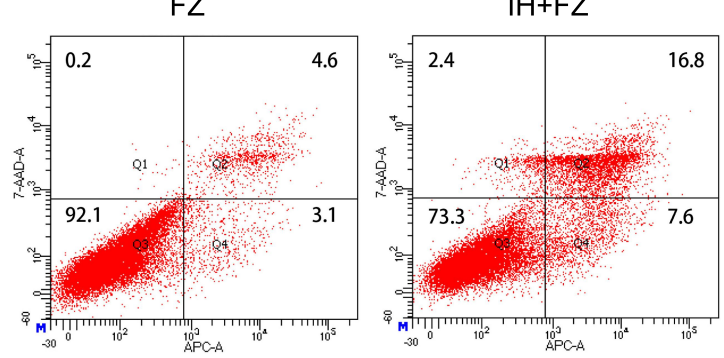

FZ+IR
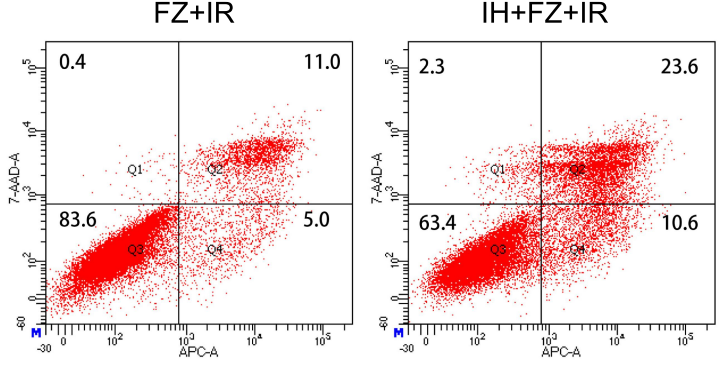

FZ

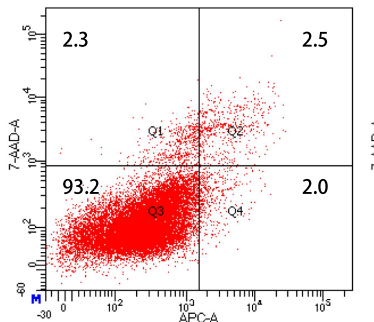

FZ+IR

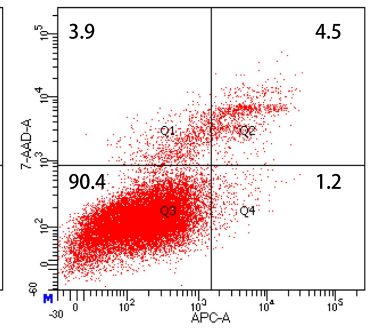

$\mathrm{IH}+\mathrm{FZ}$

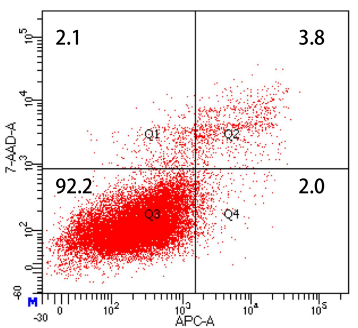

IH+FZ+IR
D

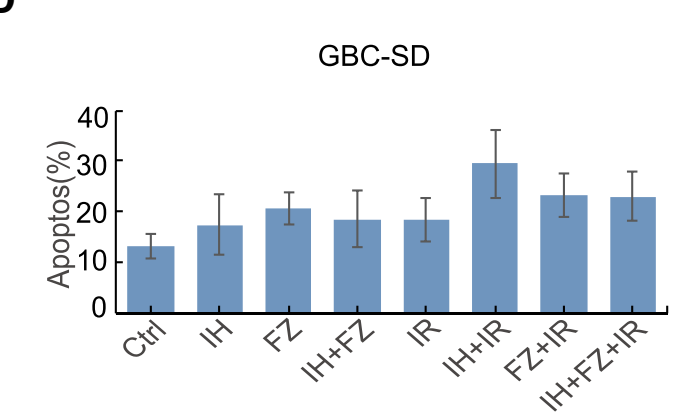

Figure 3 Effects of icotinib hydrochloride $(\mathrm{IH})$ and fluzoparib $(\mathrm{FZ})$ on irradiation-induced apoptosis. (A and B) Cell apoptosis was determined by flow cytometry in the following groups of cells: HCCC-98I0 cells pretreated with $10 \mu \mathrm{MIH}, 20 \mu \mathrm{M}$ FZ, or $10 \mu \mathrm{M} \mathrm{IH}+20 \mu \mathrm{M} \mathrm{FZ}$ at 4 hours before 6 Gy irradiation; GBC-SD cells pretreated with $15 \mu \mathrm{M} \mathrm{IH}, 5 \mu \mathrm{M} \mathrm{FZ}$, or $15 \mu \mathrm{M} \mathrm{IH}+5 \mu \mathrm{M} \mathrm{FZ}$ at 4 hours before 6 Gy irradiation. (C and $\mathbf{D})$ The percentage of Annexin V-APC-positive cells among those shown in (A and $\mathbf{B}$ ) is summarized as the apoptotic ratio and presented as the value in the $\mathrm{Y}$-axis. Error bars, $\mathrm{SD}$. ${ }^{*} \mathrm{P}<0.05$, ${ }^{* *} \mathrm{P}<0.0 \mathrm{I}$ by two-tailed Student's $t$-test; $\mathrm{n}=3$ independent experiments. 
A
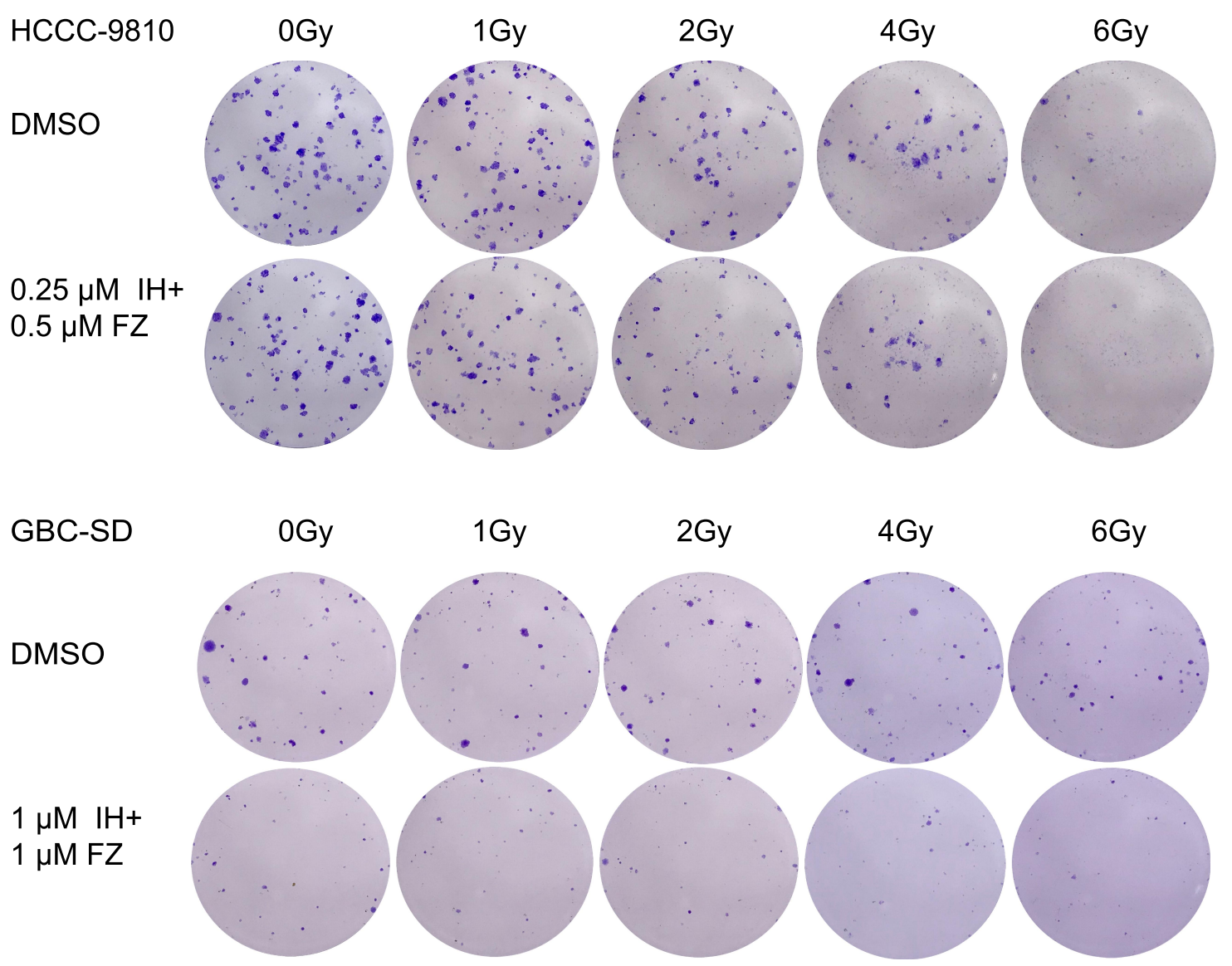

B
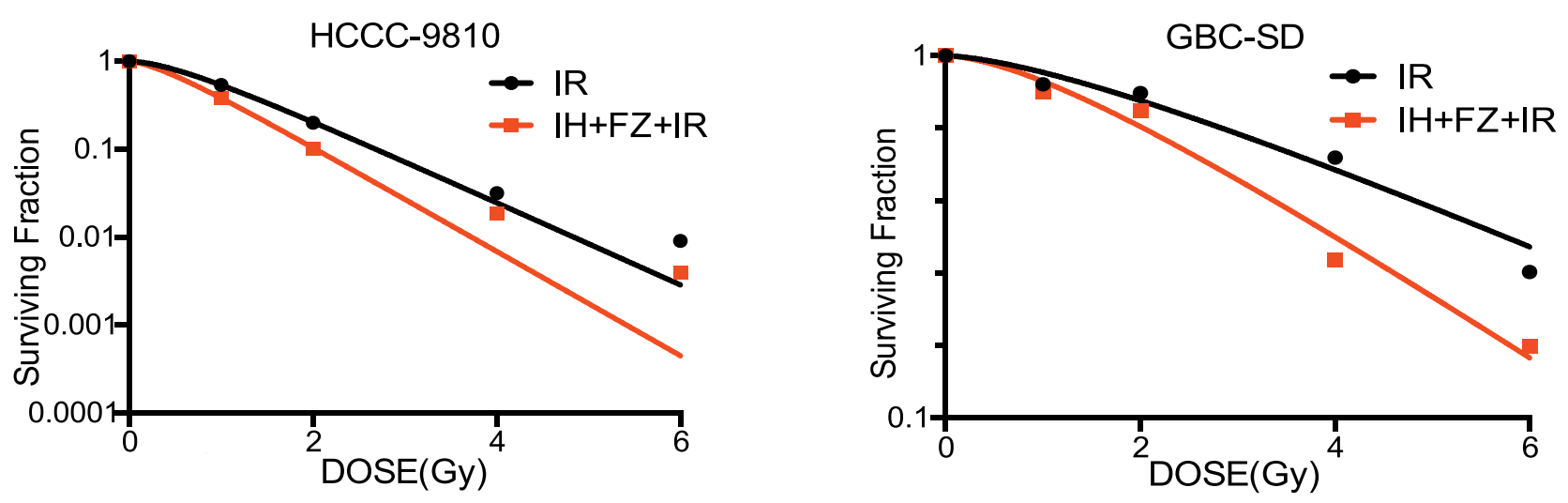

Figure 4 The combination of icotinib hydrochloride $(\mathrm{IH})$ and fluzoparib (FZ) enhanced cellular radiosensitivity. (A) A colony formation assay was performed to determine radiosensitivity in the HCCC-98I0 and GBC-SD cell lines. Cells that received $0 \mathrm{~Gy}$, I Gy, 2 Gy, 4 Gy and 6 Gy radiation were treated with DMSO or IH+FZ, respectively. (B) Clones after IR were counted and quantified to draw survival curves.

contribute to inhibiting radiotherapy-induced DNA repair through the HR pathway.

\section{Discussion}

The prognosis of BTC patients remains dismal, and treatments are limited, as there is currently no effective targeted therapy for BTC. Radiotherapy is a key strategy for many epithelial tumor types. Previous in vitro studies have shown that EGFR-TKIs and PARPis have certain radiosensitizing effects when applied in BTCs. ${ }^{5,6,8}$ However, no study has shown a two-drug combination with radiotherapy for BTC treatment. Therefore, we designed this study with the 
Table I The Parameters of a Multitarget Model Based on a Clonogenic Survival Assay

\begin{tabular}{|l|l|l|l|l|l|}
\hline Cell Line & $\mathbf{n}$ & D0 & Dq & SF2 & SER \\
\hline HCCC-98I0 IR & 1.85 & 0.93 & 0.57 & 0.20 & \\
HCCC-98I0 IH+FZ+IR & 1.63 & 0.73 & 0.36 & 0.10 & 1.27 \\
GBC-SD IR & 1.60 & $3.7 I$ & 1.73 & 0.79 & \\
GBC-SD IH+FZ+IR & 1.73 & 2.46 & 1.35 & 0.71 & 1.50 \\
\hline
\end{tabular}

Abbreviations: $n$, extrapolation number, which measures the width of the shoulder of the survival curve; D0, the dose that reduced cell survival to $37 \%$; $\mathrm{Dq}$, the intercept of the extrapolated high dose; SF2, surviving fraction at $2 \mathrm{~Gy}$; SER, sensitivity enhancement ratio; IH, icotinib hydrochloride; FZ, fluzoparib; IR, ionizing radiation.

assumption that the combination of two drugs could enhance the radiosensitivity of BTC and selected IH, an oral EGFR-TKI, and FZ, a PARPi, for study.

EGFR is an important growth factor that binds its ligands, phosphorylates the tyrosine kinase receptor and stimulates its downstream signaling pathways and therefore participates in the regulation of a number of physiological and pathological processes, including cell proliferation. ${ }^{11}$ PARPis were initially shown to be cytotoxic for cells lacking a component of the homologous recombination pathway. ${ }^{12}$ The absence of PARP-1 and PARP-2 in the presence of PARPi, activated by DNA damage resulted in hypersensitivity to ionizing radiation.

In this study, cell proliferation was inhibited under treatment with IH and FZ alone, and this inhibitory effect was much more pronounced under combined IH and FZ treatment, which indicated that these two drugs have a synergistic effect. When the two drugs were combined with radiotherapy, the inhibitory effect was more pronounced compared to that with radiotherapy alone. In the colony formation assay, the combination treatment groups of HCCC-9810 and GBC-SD cells showed radiosensitization. Therefore, this finding confirmed that $\mathrm{IH}$ combined with FZ enhanced radiation-induced proliferation inhibition in BTC cells.

IR, a common way by which DSBs are induced, causes highly toxic lesions and fatal injury in cells. When DNA damage occurs, the DDR system is activated, which can either delay the cell cycle to detect and repair the damage or induce apoptosis to eliminate cells in which a large amount of damage has accumulated. ${ }^{13}$ Flow cytometry was used in this study to investigate the impact of IH and FZ combined with IR on cell cycle distribution and apoptosis. Radiotherapy alone induced $\mathrm{G} 2 / \mathrm{M}$ phase arrest, but this was not observed in the control group. Under IH and FZ pretreatment,
S phase blockade was significantly increased compared with that upon exposure to radiation alone. Similar results were obtained in HCCC-9810 and GBC-SD cells, as the combination group showed a higher apoptotic ratio than the irradiation alone group. In summary, the results of this study suggest that the combination of IH+FZ and IR led to redistribution of the cell cycle, the inhibition of cell proliferation, augmentation of cell apoptosis and enhancement of radiotherapy efficacy.

$\gamma$-H2AX is phosphorylated at serine 139 by ataxia telangiectasia mutated (ATM) in response to DNA damage and aggregates at the DSB. ${ }^{14}$ Visualization and quantification of $\gamma$-H2AX foci using immunofluorescence staining are associated with the occurrence of DSBs, and $\gamma-\mathrm{H} 2 \mathrm{AX}$ foci serve as a DNA damage indicator to allow the evaluation of DNA damage repair efficiency. IH+FZ pretreatment significantly increased intracellular $\gamma$-H2AX focus formation compared with that upon radiation alone, and the disappearance of the foci was significantly delayed, especially in the GBC-SD cell line. The $\gamma-\mathrm{H} 2 \mathrm{AX}$ protein level was significantly increased in the $\mathrm{IH}+\mathrm{FZ}$ pretreatment group compared with the group given radiation alone at 2 hours after IR, as shown by Western blotting (Figure $6 \mathrm{C})$. These results suggest that $\mathrm{IH}$ combined with FZ could enhance radiotherapy sensitivity by increasing DSBs and blocking DNA repair progression in BTC cells.

Ionizing radiation activates the autophosphorylation of EGFR; induces the activation of downstream pathways, including the PI3K-AKT and Ras-MAPK signaling cascades; and modulate DDR to escape cell death. ${ }^{15}$ Activation of the AKT and MAPK signaling pathways can induce radioresistance, while their suppression is expected to enhance radiosensitivity. PARP plays a wide role in DNA damage repair, replication fork restart, chromatin remodeling and gene transcription. PARP-1 is the most prevalent member of the PARP family. Inhibition of PARP in DNA repair-defective tumors led to genomic instability and cell death caused by synthetic lethality. ${ }^{16}$ PARP inhibition and the consequent inhibition of PARP-facilitated DNA repair enhanced the antitumor activity of radiotherapy. ${ }^{17}$ The radiosensitization of PARP inhibitors (PARPis) has been shown affect cells in S phase of the cell cycle due to the collision of persistent single-strand breaks with replication forks and the formation of lethal DNA double-strand breaks. ${ }^{18}$ Homologous recombination (HR) is an error-free pathway of DSB repair that promotes cellular recovery from replication-blocking lesions or collapsed replication forks. RAD51, the central protein in this pathway, catalyzes DNA repair via 


\section{A}

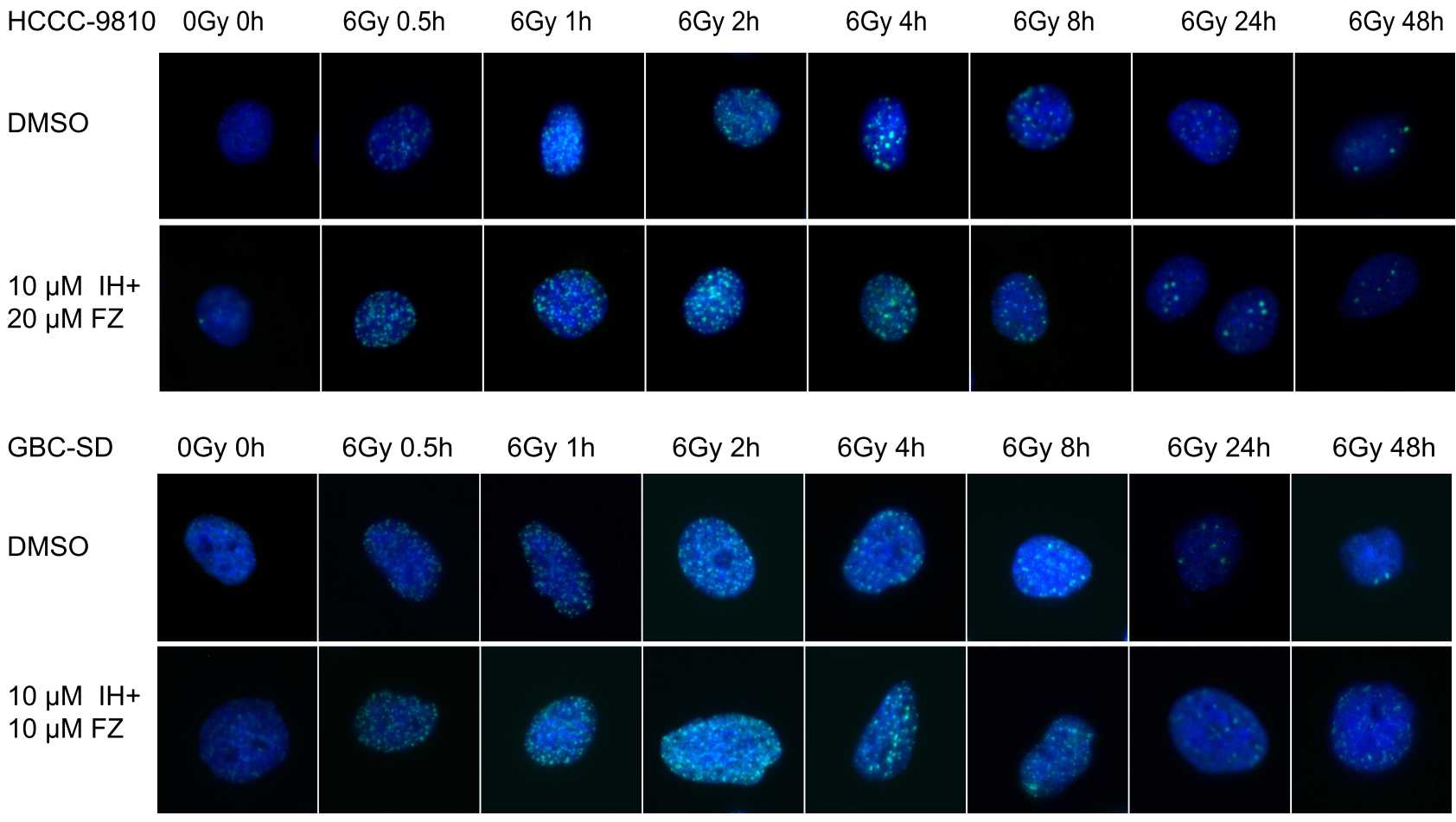

B

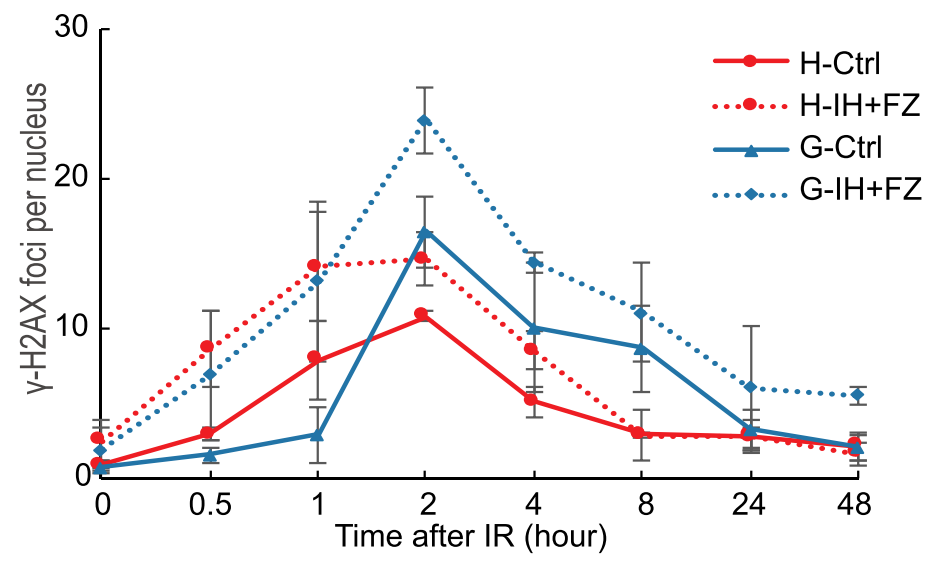

Figure 5 The combination of icotinib hydrochloride $(\mathrm{IH})$ and fluzoparib (FZ) increased IR-induced $\gamma-\mathrm{H} 2 \mathrm{AX}$ focus formation and prolonged focus retention. (A) Cells were treated with $\mathrm{IH}$ and $\mathrm{FZ}$ for 4 hours, received $0 \mathrm{~Gy}$ or $6 \mathrm{~Gy}$ radiation, and were harvested at the indicated time points before immunofluorescence. $\gamma$ - $\mathrm{H} 2 \mathrm{AX}$ foci were observed under microscopy. (B) The mean number of $\gamma-\mathrm{H} 2 \mathrm{AX}$ nuclear foci per nucleus was determined and is expressed in arbitrary units. Red curves were drawn based on the number of foci among HCCC-9810 cells, and blue curves were drawn based on the number of foci among GBC-SD cells. The means from 3 independent experiments are shown.

HR, which can ensure genomic stability. ${ }^{19}$ Because of these repair activities, EGFR-TKIs and PARP inhibitors inhibit DSB repair. The results of this study show that IH pretreatment significantly decreased the phosphorylation of MAPK and AKT, which were highly phosphorylated by radiation. Furthermore, IH plus FZ pretreatment decreased the phosphorylation of MAPK and AKT compared to that upon treatment with $\mathrm{IH}+\mathrm{FZ}$ without radiation, and the difference in p-MAPK was more pronounced than that in p-AKT. To further explain this finding, the effects of $\mathrm{IH}$ and $\mathrm{FZ}$ on RAD51 protein expression were analyzed. The results showed that the expression of RAD51 was significantly decreased by pretreatment with $\mathrm{IH}$ and $\mathrm{FZ}$ compared to that in the radiation group of BTC cells, which suggests reduced HR and enhanced genomic instability, promoting radiosensitivity. 
A

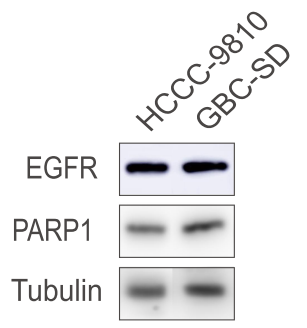

C

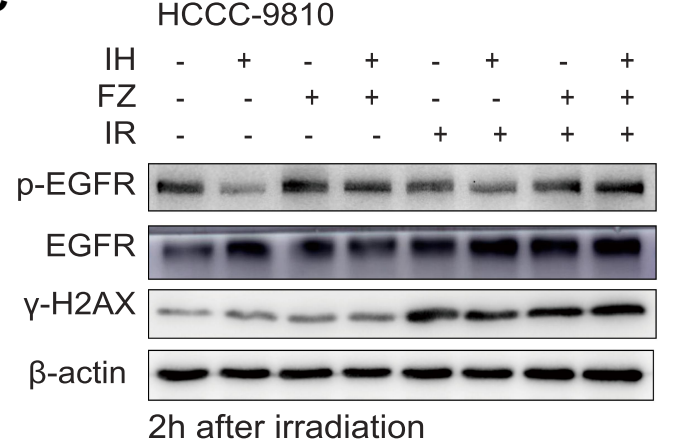

D

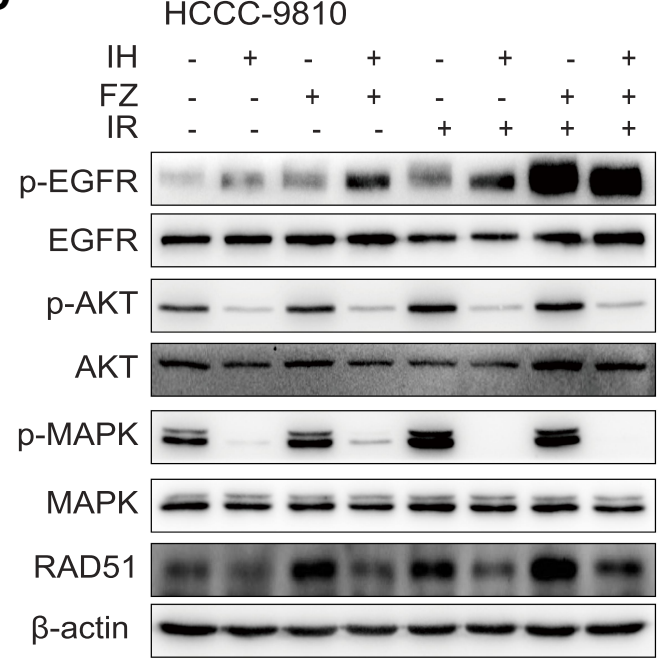

$24 \mathrm{~h}$ after irradiation

E

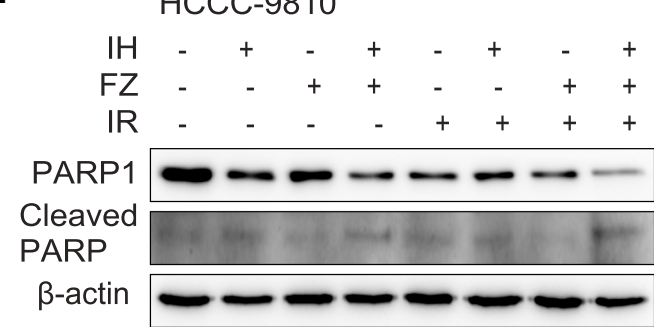

$72 \mathrm{~h}$ after irradiation

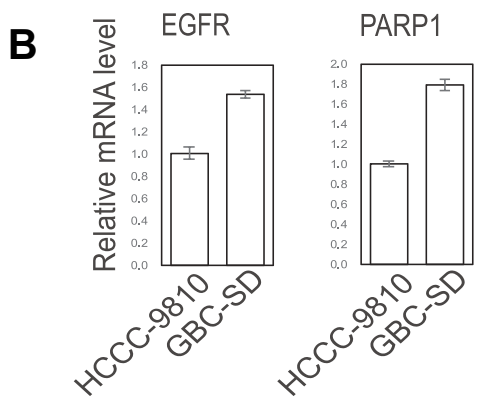

GBC-SD

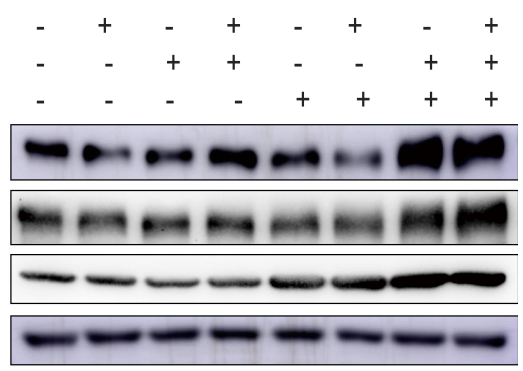

GBC-SD

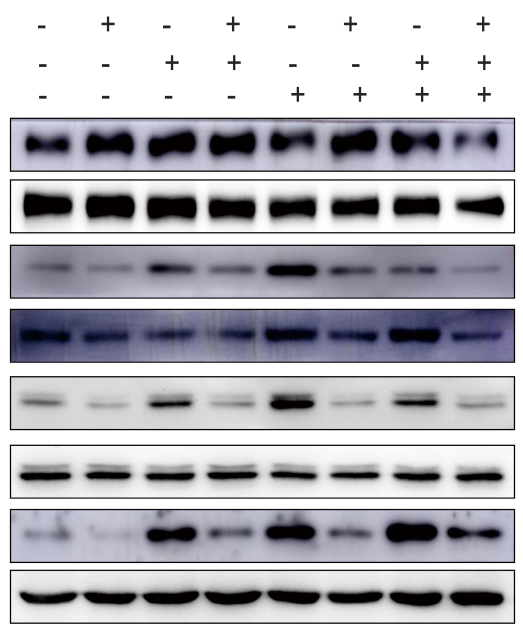

GBC-SD

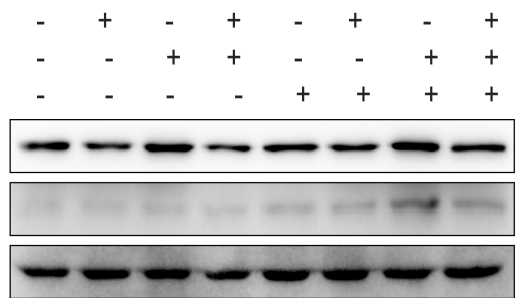

Figure 6 The combination of icotinib hydrochloride $(\mathrm{IH})$ and fluzoparib $(\mathrm{FZ})$ inhibited the EGFR signaling pathway and attenuated the radiation-induced upregulation of the HR protein RAD5I. (A and B) Western blotting and qRT-PCR were used to detect the expression levels of EGFR and PARPI in the HCCC-98I0 and GBC-SD cell lines. (C and D) Total EGFR, p-EGFR, total AKT, p-AKT, total MAPK, p-MAPK, $\gamma$-H2AX and RAD5I were detected using Western blot assays at 2 hours (C) and 24 hours (D) after radiation. (E) Total PARPI and cleaved PARPI were detected using Western blot assays at 72 hours after radiation. Data are representative of at least duplicate experiments. 


\section{Conclusion}

This study demonstrated that IH plus FZ efficiently inhibited the signaling pathway downstream of EGFR, delayed DNA damage repair and suppressed the upregulation of RAD51, thereby enhancing the sensitivity of HCCC-9810 and GBCSD cells to radiotherapy. Our work suggests $\mathrm{IH}$ and FZ combined with radiotherapy as a potent clinical therapeutic option for BTCs and that RAD51 can be used as a candidate biomarker to identify patients who might benefit from this combination therapy, but this idea needs further confirmation in preclinical mouse studies and clinical trials.

\section{Acknowledgments}

This study was supported in part by grants from the Chinese National Natural Science Foundation (Nos. 81441086 and 81672976) and Natural Science Foundation of Zhejiang Province (No. LY14H160016).

\section{Disclosure}

The authors report no conflicts of interest related to this work.

\section{References}

1. Featherstone C, Jackson S. DNA double-strand break repair. Current Biol. 1999;9(20):R759-R761. doi:10.1016/S0960-9822(00)80005-6

2. San Filippo J, Sung P, Klein H. Mechanism of eukaryotic homologous recombination. Annu Rev Biochem. 2008;77(1):229-257. doi:10.1146/ annurev.biochem.77.061306.125255

3. Maacke H, Opitz S, Jost K, et al. Over-expression of wild-type Rad51 correlates with histological grading of invasive ductal breast cancer. Int J Cancer. 2000;88(6):907-913. doi:10.1002/1097-0215(20001215) 88:6<907::AID-IJC11>3.0.CO;2-4

4. Obama K, Satoh S, Hamamoto R, Sakai Y, Nakamura Y, Furukawa Y. Enhanced expression of RAD51 associating Protein-1 is involved in the growth of intrahepatic cholangiocarcinoma cells. Clin Cancer Res. 2008;14(5):1333-1339. doi:10.1158/1078-0432.CCR-07-1381

5. Miyata H, Sasaki T, Kuwahara K, Serikawa M, Chayama K. The effects of ZD1839 (Iressa), a highly selective EGFR tyrosine kinase inhibitor, as a radiosensitiser in bile duct carcinoma cell lines. Int J Oncol. 2006. doi:10.3892/ijo.28.4.915
6. D'Andrea AD. Mechanisms of PARP inhibitor sensitivity and resistance. DNA Repair (Amst). 2018;71:172-176. doi:10.1016/j. dnarep.2018.08.021

7. Normanno N, De Luca A, Bianco C, et al. Epidermal growth factor receptor (EGFR) signaling in cancer. Gene. 2006;366(1):2-16. doi:10.1016/j.gene.2005.10.018

8. Guillot C, Favaudon V, Herceg Z, et al. PARP inhibition and the radiosensitizing effects of the PARP inhibitor ABT-888 in in vitro hepatocellular carcinoma models. BMC Cancer. 2014;14(1):1.

9. Jiang Y, Dai H, Li Y, et al. PARP inhibitors synergize with gemcitabine by potentiating DNA damage in non-small-cell lung cancer. Int J Cancer. 2019;144(5):1092-1103. doi:10.1002/ijc.31770

10. Sun X, Yang C, Liu H, et al. Identification and characterization of a small inhibitory peptide that can target DNA-PKcs autophosphorylation and increase tumor radiosensitivity. Int $J$ Radiat Oncol Biol Phys. 2012;84(5):1212-1219. doi:10.1016/j.ijrobp.2012.01.092

11. Wang X, Gu Y, Liu H, Shi L, Sun X. Icotinib hydrochloride enhances chemo- and radiosensitivity by inhibiting EGFR signaling and attenuating RAD51 expression and function in Hela $\mathrm{S} 3$ cells $</$ div $>$. Onco Targets Ther. 2018;11:1245-1258. doi:10.2147/OTT.S152613

12. Megnin-Chanet F, Bollet MA, Hall J. Targeting poly(ADP-ribose) polymerase activity for cancer therapy. Cell Mol Life Sci. 2010;67 (21):3649-3662. doi:10.1007/s00018-010-0490-8

13. Chapman JR, Taylor Martin RG, Boulton Simon J. Playing the end game: DNA double-strand break repair pathway choice. Mol Cell. 2012;47(4):497-510. doi:10.1016/j.molcel.2012.07.029

14. Mah LJ, Orlowski C, Ververis K, Vasireddy RS, El-Osta A, Karagiannis TC. Evaluation of the efficacy of radiation-modifying compounds using gammaH2AX as a molecular marker of DNA double-strand breaks. Genome Integr. 2011;2(1):3. doi:10.1186/ 2041-9414-2-3

15. Herbst R, Bunn P. Targeting the epidermal growth factor receptor in non-small cell lung cancer. Clin Cancer Res. 2003.

16. Irshad S, Ashworth A, Tutt A. Therapeutic potential of PARP inhibitors for metastatic breast cancer. Expert Rev Anticancer Ther. 2011;11(8):1243-1251. doi:10.1586/era.11.52

17. de Haan R, van Werkhoven E, van den Heuvel MM, et al. Study protocols of three parallel Phase 1 trials combining radical radiotherapy with the PARP inhibitor olaparib. BMC Cancer. 2019;19:1. doi:10.1186/s12885-019-6121-3

18. Dungey FA, Löser DA, Chalmers AJ. Replication-dependent radiosensitization of human glioma cells by inhibition of poly (ADP-ribose) polymerase: mechanisms and therapeutic potential. Int J Rad Oncol Biol Phys. 2008;72(4):1188-1197. doi:10.1016/j. ijrobp.2008.07.031

19. Mason JM, Logan HL, Budke B, et al. The RAD51-stimulatory compound RS-1 can exploit the RAD51 overexpression that exists in cancer cells and tumors. Cancer Res. 2014;74(13):3546-3555.

\section{Publish your work in this journal}

Cancer Management and Research is an international, peer-reviewed open access journal focusing on cancer research and the optimal use of preventative and integrated treatment interventions to achieve improved outcomes, enhanced survival and quality of life for the cancer patient.
The manuscript management system is completely online and includes a very quick and fair peer-review system, which is all easy to use. Visit http://www.dovepress.com/testimonials.php to read real quotes from published authors. 